УДК 37.015 .31

\title{
Аспекты восприятия смешанного форматов обу- чения у студентов 1 курса ВУЗа и особенности их академической мотивации
}

\author{
Мария В. Манкова \\ Южный федеральный университет, г. Ростов-на-Дону, Российская Федерация \\ E-mail: mankova@sfedu.ru \\ ORCID ID: https://orcid.org/0000-0002-1696-5777
}

\section{Аннотация}

В статье представлены результаты исследования аспектов академической мотивации, уровня смысложизненных ориентаций, и отношений к Аистанционному и смешанному формату обучения у студентов бакалавриата первого года обучения. Во ВвеАении дается теоретический обзор понятий акалемической мотивации, и смешанного формата обучения. Актуальность Аанной темы объясняется современными тенденциями к цифрровизации высшего образования, особенно усилившейся в последние несколько ^ет. Научная новизна заключается в изучении особенностей акалемической мотивации и отношения к очному и Аистанционному формату обучения студентов 1 курса, которые поступили в университет в условиях ограничений, связанных с пандемией COVID-19 в 2020 году. В разделе Методы описываются организация исследования и примененные методики: тест смысложизненных ориентаций А. А. Аеонтьева; опросник «Шкала академической мотивации» Т. О. Горлеева, О. А. Сычева и Е. Н. Осина; авторский опросник, выявляющий отношение к смешанному формату обучения. Были описаны особенности выборки, вылвинутые гипотезы, и перечислены использованные методы математической статистики. В разделе Результаты представлены обработанные данные. По итогам опроса большая часть студентов отметила прежний уровень мотивации к обучению после поступления в университет, а те, кто отметил его повышение - более удовлетворены качеством образования, чем те, кто отметил, что уровень остался прежним или снизился. Также авторский опросник позволил выявить, что смешанный фрормат обучения Аля большинства первокурсников не мешает ощущению пребывания в еАином образовательном пространстве. Корреляционный анализ выявил связь межАу уровнем осмысленности жизни и мотивацией познания, а также тенденцию к обратной связи межАу уровнем осмысленности жизни и значимостью фрормата обучения у респондентов. В ОбсужАении результатов представлено сравнение полученных $А$ анных, с уже проведенными исследованиями на Аанную тематику. В Заключении Ааны выводы по всей проведенной работе, и возможные перспективы А^я Аа^ьнейших исслеАований. 


\title{
КАючевые слова
}

обучение, студент, университет, смешанное обучение, академическая мотивация, Аистанционные занятия

\section{Для цитирования}

Манкова М. В. Аспекты восприятия смешанного форматов обучения у студентов 1 курса ВУЗа и особенности их академической мотивации // Инновационная наука: психология, педагогика, дефектология. 2021. Т. 4, No 4. C. 52-70. doi: https://doi.org/10.23947/2658-7165-2021-4-4-52-70

\section{Aspects of the perception of mixed learning formats among 1st year students of the university and the features of their academic motivation}

\author{
Maria V. Mankova \\ Southern Federal University, Rostov-on-Don, Russian Federation \\ E-mail: mankova@sfedu.ru \\ ORCID ID: https://orcid.org/0000-0002-1696-5777
}

\begin{abstract}
The article presents the results of a study of aspects of academic motivation, the level of life-meaning orientations, and attitudes towards a mixed learning format among first-year undergraduate students. The Introduction provides a theoretical overview of the concepts of academic motivation and blended learning. The relevance of this topic is explained by the current trends towards the digitalization of higher education, which has especially intensified in the past few years. The scientific novelty lies in the study of the features of academic motivation and attitudes towards full-time and distance learning of 1st year students, who entered the university under the constraints associated with the COVID-19 pandemic. The Methods section describes the techniques used: test life orientations D. A. Leontiev; questionnaire "Scale of academic motivation" T. O. Gordeeva, O. A. Sycheva and E. N. Osin; the author's questionnaire was also created, revealing the attitude towards the blended learning format. The features of the sample were described, the hypotheses put forward, and the methods of mathematical statistics used were listed. The Results section displays the processed data. According to the results of the survey, most of the students noted the previous level of motivation to study after entering the university, and those who noted its increase were more satisfied with the quality of education than those who noted the previous or decreased level. The survey showed that the blended learning format for most students does not interfere with the feeling of being in a single educational space. Correlation analysis revealed a positive link between the level of
\end{abstract}


ПЕДАГОГИЧЕСКАЯ ПСИХОЯОГИЯ

meaningfulness in life and the motivation for cognition, as well as a tendency towards a negative link between the level of meaningfulness in life and the importance of the learning format among respondents. In the Discussion of the results, a comparison of the obtained data is presented, with already conducted studies on this topic. In the Conclusion, conclusions are given on all the work carried out, and possible prospects for further research.

\section{Keywords}

learning, student, university, blended learning, academic motivation, distance learning

\section{For citation}

Mankova M. V. (2021). Aspects of the perception of mixed learning formats among 1st year students of the university and the features of their academic motivation. Innovative Science: psychology, pedagogy, defectology, 4(4), 52-70. doi: https://doi. org/10.23947/2658-7165-2021-4-4-52-70

\section{Введение}

Академическая мотивация, так же понимаемая как мотивация к учебной и познавательной деятельности, может определяться как некоторая сумма психологических причин, которые могут объяснить стремления к учебе, взывающие к учебно-познавательной активности, а также поддерживающие ее во время свершения этой деятельности. Более высокий уровень мотивации позволяет усвоить большее количество учебной информации и, в конечном счете, может повышать качество образования в целом. Мотивация учебной деятельности может включать не только дичностные мотивы, но также и уровень навыков коммуникации, свойства дичности и психологические особенности обучающихся (Цибульникова, 2021; Швецова, 2020).

Мотивация состоит из системы мотивов, которые могут пониматься как осознанные иди нет причины (побуждения) выполнения определенной (в данном случае учебной) деятельности индивидом. Оценка данного вида мотивации осуществляется по силе, качеству и месту в иерархии других мотивов. Совокупность обозначенных критериев может вдиять на эффективность и работоспособность студента и влиять на его состояние психики (Носкова, Бескова и Булыгина, 2016).

Сущность содержания и аспектов проявления учебной мотивации отражены в работах Т. О. Гордеевой, где выделяется два типа мотивации:

- - Внутренняя, создаваемая мотивами удовлетворения потребностей в познавании, саморазвития и желанием достижений.

- - Внешняя, зависящая от сторонних обучению потребностей, таких как нужда в независимости, в принятии и в уважении (Гордеева, Сычев и Осин, 2014). Оба типа мотивации направляются на борьбу с фрустрированностью 
потребностей, относящихся к деятельности, или же на их удовлетворение и адекватны содержанию учебной активности. В своей методике для определения уровня академической мотивации, Т. О. Гордеева, О. А. Сычев и Е. Н. Осин, к внутренним мотивам относят такие виды мотивов как мотивы достижения, познания и саморазвития, а к внешним - мотивы самоуважения, интроецирования и экстернальные мотивы (Гордеева, Сычев и Осин, 2014).

B теории самодетерминации E. Deci, R. Ryan в зависимости от потребности в автономии (возможности управления своими действиями) авторами выделяется следующие виды регуляции: интроецированная, экстернальная, интегрированная и идентифицированная. При этом экстернальная и интроецированные формы являются менее эффективными, так как имеют связь с реакциями на малое количество достигнутого и трудности результатов деятельности (Deci \& Ryan, 2007).

В последние 2 года (2020-2021) условия обучения студентов высших учебных заведений кардинально изменились. В условиях пандемии дистанционные образовательные технологии получили интенсивное развитие вследствие необходимости их использования из-за ограниченной социальной активности. После ослабления ограничений в университетах стал активно применяться смешанный формат обучения (Баранов, 2020).

Смешанное обучение (Blended Learning) - учебный формат, сочетающий аудиторные занятия, требующие очного присутствия всех участников учебного процесса, с дистанционным обучением, когда занятие проводится посредством электронных технологий, при помощи передачи видео, аудио, текстовой информации. Такой подход может объединять подожительные стороны обоих типов проведения занятий, и даже образовывать эффективно функционирующую систему при грамотном его применении. Считается, что до 30 \% времени обучения в дистанционном режиме - это традиционный формат обучения с поддержкой дистанционных образовательных технодогий; от 30 \% до 80 \% - собственно смешанное обучение; от 80 \% и выше - полноценное дистанционное обучение.

В связи с распространением смешанного обучения появляется всё больше исследований, которые описывают раздичные психодогические, педагогические и социальные эффекты, возникающие при применении такого формата: факторы создания культуры смешанного обучения (Long \& Van Hanh, 2020), разработка особых педагогических стратегий (Pannan \& Legge, 2016) и многие другие.

К. Г. Кречетников выделяет следующие особенности эффективного смешанного обучения: направленность на каждого обучаемого (персонадизация обучения), проверка должного уровня знаний (для перехода к изучению более сложного), ориентировка на получение достижений (повышение мотивации) и на отношения (между действующими участниками процесса), и самоответственность обучающегося (возможность регулировать свою скорость усвоения и прохождения учебных тем) (Кречетников, 2019). 
ПЕДАГОГИЧЕСКАЯ ПСИХОЯОГИЯ

Из положительных сторон К. Г. Кречетников отмечает уменьшение очных занятий, и следовательно, тратящегося на дорогу времени до университета; надичие аудиторных занятий позволяет проводить обсуждение изучаемого предмета непосредственно, вероятно, с большим погружением в тему; очные занятия не дают проявиться недостатку в коммуникации дицом к лицу и слабым навыкам выступления; стоит отметить возможность более комфортного распределения времени на обучение и повторение материала самостоятельно, а также чередовать периоды продуктивности и отдыха; большое количество разных видов активности; большая доступность учебных материалов, возможность поиска и нахождения информации более быстро, разнообразие в плане возможностей для восприятия информации (совмещение аудио, текста и видео), а также возможность пересмотра записи занятий и доступ к пройденному материалу.

К минусам смешанного образования относят: малое количество знаний работы с электронной средой у участников образовательного процесса, что затрудняет прогресс обучения; возможное неумение организовать свое время студентами; вероятное отсутствие самостоятельного интереса к изучаемому сверх обязательного; малая обеспеченность техническими средствами; сложности с составлением равномерной учебной нагрузки (Кречетников, 2019). Большая часть получаемых знаний может не усваиваться не до конца, и при преумножении объема за счет повторений (дублирования), при создании избытка информации, шанс на лучшее усвоение знаний (особенно при наличии самостоятельной регуляции обучения у студента) повышается (Балашова, 2021).

Зарубежные исследователи Н. Staker, M. Horn, выделяют несколько моделей смешанного обучения:

- Дицом к дицу, когда большая часть занятий проходит в аудитории в присутствии преподавателя;

- ротационная модель, сочетающая чередование очных занятий и самостоятельных занятий онлайн;

- гибкий график, когда студент обращается к преподавателю по вопросам его собственного учебного плана в удобное для него время;

- онлайн-лаборатория, с проведением занятий в специальных виртуальных классах;

- самостоятельное обучение, с возможностью у студента самому выбирать учебные курсы дия изучения;

- онлайн встречи, когда аудиторные занятия крайне редки, и основное обучение проводится онлайн, асинхронно (при уже записанном занятии) иди синхронно (занятие проходит в режиме настоящего времени) (Staker \& Horn, 2012). 


\section{Методы}

Объектом исследования стали студенты 1 курса Южного федерального университета направления «Психология», в количестве 74 человек, из них 68 (91,9\%) - женщины, и 6 (8,1\%) - мужчины в возрасте от 17 до 23 лет. Респонденты отвечали на вопросы в период с 23 по 27 марта 2021 г., сбор ответов осуществлялся с помощью Google Forms. Респонденты принимали участие в опросе добровольно.

Для исследования особенностей академической мотивации и аспектов восприятия студентами первого курса смешанного формата обучения были исподьзованы следующие методики: тест смысложизненных ориентаций Д. А. Леонтьева (Деонтьев, 2000), шкала академической мотивации О. Гордеева, О. А. Сычева и Е. Н. Осина (Гордеева, Сычев, Осин, 2014), а также специально разработанная авторская анкета-опросник.

Авторский опросник включал в себя 22 вопроса. Он содержал как открытые вопросы, так и вопросы, которые вкдючади несколько вариантов ответа иди шкалу от 1 до 10, где наибодьшие значения были у вариантов полюса характеризующие высокую мотивацию учиться, вкдюченность, меньшую значимость формата обучения, удовлетворенность, комфорт, и ощущение пребывания в едином образовательном пространстве.

Для обработки данных, полученных в ходе проведения исследования, быди исподьзованы методы математической статистики: корреляционный анализ при помощи непараметрических критериев: коэффициента корреляции r-Спирмена и критерия Н Краскала - Уоллеса.

\section{Резудьтаты}

Вопросы анкеты-опросника можно условно разделить на пять блоков: особенности академической мотивации $(11,12,16,17)$; единение с группой и образовательной средой $(5,9,21)$; аспекты коммуникации в дистанционном формате (8, $18)$; сравнение лекционных и практических занятий $(3,4,6,7)$; значение формата обучения $(10,19,20,22)$.

В первом блоке «Особенности академической мотивации» рассматриваются вопросы касающиеся удовлетворенности ожиданий от образования и мотивации к обучению.

Вопрос 11 звучал как: «Удовлетворены ди Ваши ожидания в качестве образования после поступления в университет, в условиях карантина?», испытуемым предлагалось выбрать цифру по шкале от 1 до 10, где 1 - неудовлетворенность, а 10 - удовлетворенность. Медиана ответов по данному вопросу - 6, что говорит о том, что средний испытуемый из представленной выборки чуть более склонен считать себя удовлетворенным в плане ожиданий от поступления в университет в сложившихся условиях.

В вопросе 12: «Изменилось ли Ваше желание получить высшее образование 
ПЕДАГОГИЧЕСКАЯ ПСИХОЯОГИЯ

в условиях карантина?», 64 (86,5\%) отметили, что их желание осталось прежним, у 5 (6,8\%) респондентов желание снизилось, и у стольких же-повысилось.

Медиана ответов вопроса 16 («Как вы оцениваете свое желание выполнять задания для дистанционных занятий?», по шкале от 1 до 10, где 1 - желание низкое, а 10 - желание высокое) равна 8, что говорит о более выраженном предпочтении большинства выполнять задания для удаленных пар.

Результаты вопроса 17: «Как Вы считаете, в целом, изменилась ли ваша мотивация к обучению в университете при обучении на смешанном формате?» показали, что 54 (73\%) респондента считают что их мотивация осталась прежней, 11 (14,9\%) отметили снижение мотивации, и повышение отметило лишь 9 (12,2\%) человек.

В блоке «Единение с группой и образовательной средой» были рассмотрены аспекты касающиеся чувства единения при дистанционном формате обучения.

В вопросе 5 «Ощущаете ли Вы единство с группой во время дистанционных занятий?», со шкалой от 1 до 10, где 1 - не ощущаю, а 10 - отчетливо ощущаю, согласно медиане равной 7, более половины студентов испытывают чувство единства с группой на удаленных занятиях.

По полученным результатам вопроса 9 «Возникало ли у Вас чувство отчужденности от процесса обучения при смешанном формате обучения?» 29 (39,2 \%) его не испытывают, у 32 (43,2 \%) студентов оно возникает редко, 6 (8,1\%) испытывают часто, и у 7 (9,5\%) это чувство присутствует практически всегда (рис. 1). Таким образом для данной выборки обучающихся не характерна отчужденность от образовательного процесса при смешанной форме обучения.

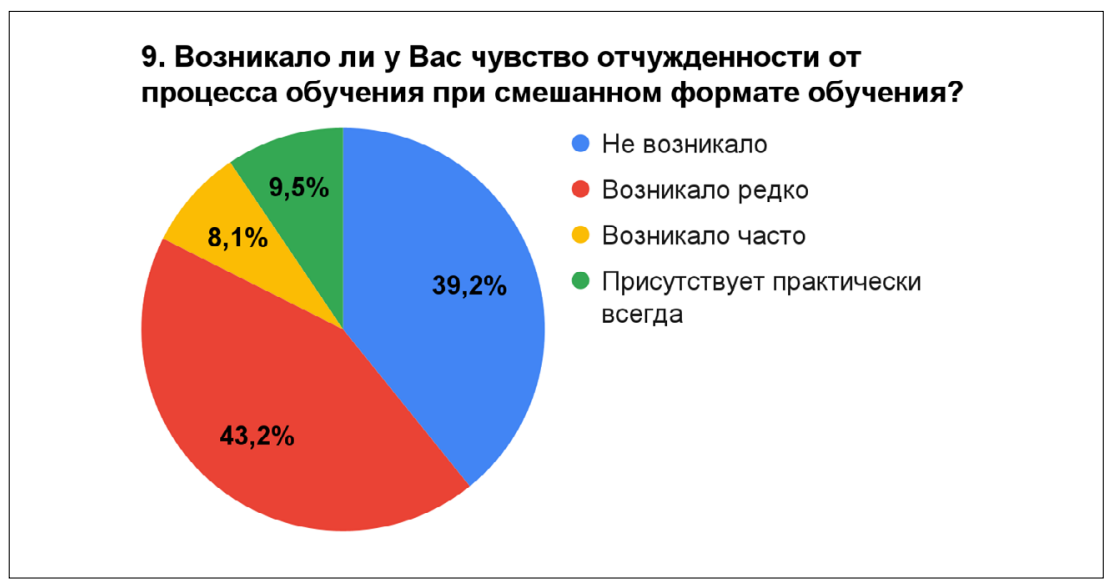

Рисунок 1. Результаты вопроса № 9 анкеты-опросника 
В ответах на вопрос 21 «Насколько вы чувствуете, что пребываете в едином образовательном пространстве с преподавателями и другими студентами в те дни, когда у вас дистанционные занятия?», со шкалой от 1 до 10, где 1 - чувствую, что отдален от образовательного пространства, а 10 - чувствую, что пребываю в образовательном пространстве, была выявлена медиана равная 8, свидетельствующая о том, что большая часть студентов-первокурсников из данной выборки более ощущают себя пребывающими в образовательном пространстве во время дистанционных дней.

Следующий блок «Аспекты коммуникациии в дистанциинном формате» повествует об особенностях и влиянии трудностей на контакт между участниками занятия.

Вопрос 8 «Насколько вам легко вести диалог с преподавателем, другими участниками собрания, если вы не видите их непосредственно?», со шкалой от 1 до 10, где 1 - дается с трудом, а 10 - дается легко, показал, что респонденты более считают, что им легко вести диалог без непосредственного общения, чем признают трудность этого процесса (медиана равна 8).

По результатам вопроса 18 «Как вы думаете, вдияют ди помехи, проблемы со связью на процесс проведения дистанционных занятий?» было выявлено, что 5 (6,8 \%) студентов не считают проблемы со связью достаточно вдиятельными для процесса проведения занятий дистанционно, 45 (60,8 \%) признают незначительное влияние, и 24 (32,4\%) отмечают сильное влияние технических проблем.

В блоке «Сравнение лекционных и практических занятий» вопросы, позволяющие сопоставить мнения касательно восприятия формата на разных типах занятий.

В 3 вопросе анкеты-опросника «Насколько Вам комфортно находиться на лекции дистанционно, без возможности видеть остальных участников?», со шкалой от 1 до 10, где 1 - некомфортно, а 10 - комфортно, с медианой равной 9 , оказалось так, что средний респондент в достаточно бодьшой степени будет ощущать комфорт на дистанционной лекции (рис. 3). Тогда как в 4 вопросе, с аналогичной формулировкой и шкалой, но с разницей вопроса о комфорте на практических занятиях - удалось установить медиану равную 8, показывающую, что больше половины студентов также испытывают комфорт на практическом занятии, но меньше, чем на лекционном, проводимом дистанционно в обоих случаях (Рис. 2). 


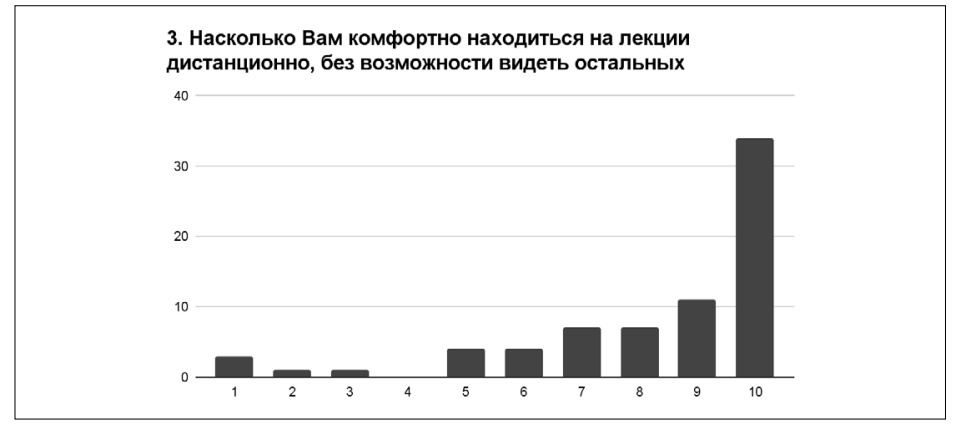

Рисунок 2. Результаты вопроса № 3 анкеты-опросника

В вопросе 6 и 7, о трудностях с включенностью на дистанционных лекционных, и дистанционных практических занятиях, со шкалой от 1 до 10, где 1 - мне сложно вкдючиться в процесс, а 10 - мне легко вкдючиться в процесс, получидись медианы 7 и 8 соответственно, что говорит о том, что большинству испытуемых достаточно легко дается включение в процесс обучения на лекциях, и чуть более проще сделать это на практических удаленных занятиях.

Последний блок «Значение формата обучения» включал в себя вопросы о важности формата обучения в сравнение с другими особенностями.

В вопросе 10 «Получаете ли Вы удовольствие от учебы вне зависимости от формата обучения?» большинство испытуемых (50 (67,6\%) получают удовольствие вне зависимости от формата обучения, 9 (12,2\%) его получают только на очном, и только на дистанционном (в обоих случаях), и лишь $6(8,1 \%)$ вне зависимости от формата не получают удоводьствия от учебы.

Следующие два вопроса касаются значимости формата обучения, в 19 - при наличии интереса и личностного смысла к предмету, и в 20 -если преподаватель сам вовлечен и заинтересовывает предметом. В обоих вопросах предлагалось выбрать цифру от 1 до 10, где где 1 - формат имеет большое значение, а 10 - формат не имеет значения. В вопросе 19 «Имеет ли значение формат обучения (очный или дистанционный), если предмет интересен, имеет для вас личностный смысл?» медиана ответов равна 9, что говорит о выраженном предпочтении большинства представителей выборки считать формат обучения не столь значимым, при наличии их личной заинтересованности. В 20 вопросе «Имеет ли значение формат обучения, если преподаватель сам вовлечен, заинтересовывает предметом?» медиана - 9,5, что тоже показывает для подавдяющей части респондентов считать формат не столь важным, при наличии умения заинтересовать у преподавателя.

В вопросе 22 «В каком формате вам хотелось бы продолжать обучение?» полностью очно продолжить учиться предпочитает - 7 (9,5\%) человек, 
а дистанционно - 14 (18,9\%) респондентов, тогда как бодьшинство из ответивших (53 (71,6 \%)) предпочли бы продолжить обучение в смешанном формате.

Респонденты, в ходе исследования прошли методику: «Тест смысложизненных ориентаций» (СЖО) Д. А. Аеонтьева, по результатам которой было выявлено, что у большей части респондентов общий уровень осмысленности жизни - средний $46(62,2 \%)$, у 20 (27\%) - высокий, и у 8 (10,8\%) - низкий.

Далее был проведен корреляционный анализ, при помощи статистического пакета SPSS-22, с использованием непараметрического метода - коэффициента корреляции r-Спирмена.

В результате анализа были обнаружены статистически значимые корреляционные связи между вопросами составленной анкеты-опросника, а также шкалами методики СЖО и «Шкалы академической мотивации».

В результате корреляционного анализа полученных данных между № 3 и № 4 вопросами была обнаружена положительная корреляционная связь средней силы $(0,659)$, статистически значимая на уровне 0,01 . Исходя из полученных данных, и табл. 1, можно сделать вывод, что чем выше студенты оценивают комфорт на дистанционных лекциях, тем бодьше они оценивают свой комфорт на дистанционных практических занятиях. Так же, те кто более склонны испытывать комфорт на дистанционной лекции имеют более высокую оценку своего единения с группой во время дистанционных занятий (вопрос № 5) $(0,596$ при r=0,01), более удовлетворены качеством образования после поступления в университет в условиях карантина (вопрос № 11) (0,598 при r=0,01), более чувствуют свое пребывание в едином образовательном пространстве во время дистанционных дней (вопрос № 20) (0,647 при r=0,01), и тем менее важен формат занятия при наличии вовлеченного в предмет преподавателя (вопрос № 21) (0,568 при r=0,01).

Также была выявлена положительная корреляция средней силы связи $(0,672)$ при уровне статистической значимости 0,01 между вопросами № 4 и № 21. Это значит, что те, кто ощущает больший комфорт на дистанционном практическом занятии будут более склонны ощущать свое пребывание в едином образовательном пространстве с другими студентами и преподавателями.

Между вопросами № 5 и № 21 была обнаружена положительная корреляционная связь средней сиды $(0,684)$, статистически значимая на уровне 0,01 . Так, те студенты, ощущающие свое единство больше чувствуют себя более причастными к единому образовательному пространству, а еще более высоко оценивают свое желание выподнять задания на дистанционных занятиях (вопрос № 16) (0,565 при r=0,01).

Между вопросами № 6 и № 7 была выявлена положительная средняя связь $(0,641)$, которая показывает тенденцию наличия меньших сложностей со включенностью на лекционных занятиях, у тех, кто испытывает их меньше и на практических занятиях проводимых дистанционно. Можно также сказать, что у тех, 
ПЕДАГОГИЧЕСКАЯ ПСИХОЯОГИЯ

кому легче включиться на дистанционных лекциях присутствует большее желание выполнять задания для дистанционных занятий (вопрос № 16) (0,584 при $\mathrm{r}=0,01)$, и более выраженное чувство пребывание в едином образовательном пространстве во время дистанционных занятий (вопрос № 21) $(0,575$ при r=0,01).

Была установлена положительная средняя корреляционная связь между вопросами № 8 и № 21 (0,644 при r=0,01), показывающая большую выраженность ощущения пребывать в едином образовательном пространстве во время дистанционных дней у тех, кому проще вести диалог на дистанционных занятиях.

По результатам анализа также было выявлено, что те, кто более удовлетворен качеством образования после своего поступления в университет (вопрос № 11) признают большее желание выполнения заданий для дистанционных занятий (вопрос № 16) (0,591 при r=0,01), и ощущают большее чувство пребывания в едином образовательном пространстве в дистанционные дни (вопрос № 21) $(0,573$ при r=0,01).

Была обнаружена и связь между вопросами № 20 и № 21, средняя по силе $(0,647)$, и статистически значимая на уровне 0,01 . Из этого следует, что чем меньше имеет значение формат обучения, при наличии увлеченного предметом преподавателя, тем более студенты ощущают свое пребывание в едином образовательном пространстве. Т. е. ощущение пребывания в одном образовательном пространстве может увеличиваться при наличии заинтересованного в своей дисциплине преподавателя. Также те, кто более явственно ощущают свое пребывание в образовательном пространстве при вышеупомянутых условиях, испытывают большее желание выполнять задания для дистанционных занятий (вопрос № 16) (0,635 при r=0,01).

Кроме этого, между вопросами № 19 и № 20 была обнаружена сильная положительная связь $(0,786)$, при уровне значимости 0,01 . Что означает, что для тех студентов, которым более важно наличие личностного смысла, также очень важно наличие заинтересованного в своем предмете преподавателя, чем сам формат обучения.

Между шкалой методики академической мотивации «мотивацией познания», и общим показателем осмысленности жизни была выявлена средняя положительная связь (0,544 при $\mathrm{r}=0,01)$, показывающая тенденцию, что чем больше будет показатель общей осмысленности жизни, тем более будет больше мотивация познания.

Были обнаружены очень слабые, но тем не менее статистически значимые корреляции между шкалами показателей методики, выявляющей уровень академической мотивации, и между вопросами составленной анкеты-опросника.

Между показателем познавательной мотивации и вопросами о значимости формата обучения, при наличии собственного интереса к предмету, и при наличии у преподавателя интереса или умения заинтересовать предметом были выявлены положительные связи - 0,264 (при r=0,05) и 0,240 (при r=0,05) 
соответственно, что показывает скдонность считать формат менее значимым, при надичии интереса собственного или умеющего заинтересовать предметом преподавателя, у тех у кого более высокий уровень познавательной мотивации. Также у склонных считать формат менее значимым при наличии интереса у себя, и у преподавателя будет больше вероятность большего уровня мотивации достижения $((0,291$ при $\mathrm{r}=0,05)$ и $(0,253$ при $\mathrm{r}=0,05)$ соответственно).

Уровень экстернальной мотивации, которая связана со стремлением избежать проблем и соответствовать общественным требованиям, будет тем более высокий, чем более важен формат, и чем менее важно наличие интереса у преподавателя к преподаваемому предмету $(-0,235$ при $\mathrm{r}=0,05)$.

Несколько более высокий уровень амотивации, т. е. стремления к избеганию учебной деятельности, у тех, кто считает формат более значимым, чем наличие личностного смысла изучать предмет $(-0,255$ при $\mathrm{r}=0,05)$, и наличии умеющего заинтересовать предметом преподавателя $(-0,299$ при $\mathrm{r}=0,01)$.

Исходя из приведенных корреляций, можно сделать вывод, о тенденции к тому, что чем менее присутствует интерес к учебной деятельности и чем менее осмыслена учебная деятельность, тем большее значение будет иметь формат проведения занятий для студентов первого курса.

В ходе анализа полученных данных был применен критерий Н Краскала Уоллеса, позводивший выделить раздичия в условно выделенных подгруппах, по 17 вопросу, и таким образом было проведено сравнение трех подгрупп студентов, отметивших, снизилась, осталась прежней или увеличилась их мотивация к обучению в университете при обучении на смешанном формате. Было проведено сравнение по выраженности характеристик показателей осмысленности жизни и показателей шкал академической мотивации. В результате применения критерия были выделены статистически значимые раздичия у выделенных подгрупп студентов первого курса по вопросам созданной анкеты с отметкой выраженности по шкале от 1 до 10.

Были обнаружены значимые раздичия по 5 вопросу, в котором большие отмеченные значения означают большее ощущение единения с группой во время дистанционных занятий. Большая часть отметивших повышение мотивации к обучению в университете при обучении на смешанном формате отмечают большее ощущение единения, чем отметившие понижение мотивацию, и те кто отметия ее оставшейся прежней (рис. 3). 


\section{Критерий Краскала-Уоллиса для независимых выборок}

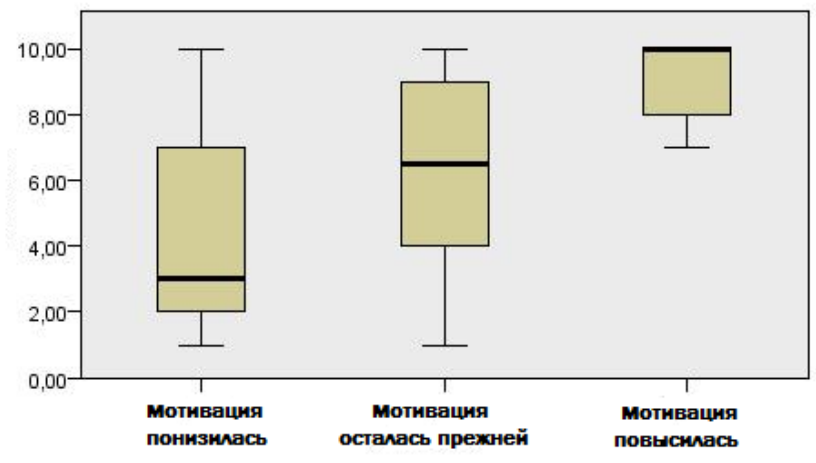

\begin{tabular}{|lr|}
\hline Всего & 74 \\
\hline Статистика критерия & 10,831 \\
\hline Степени свободы & 2 \\
\hline $\begin{array}{l}\text { Асимптотическая знч. (2- } \\
\text { сторонний критерий) }\end{array}$ &, 004 \\
\hline
\end{tabular}

Рисунок 3. Различия по ощущению еАинства с группой во время Аистанционных занятий

Отметившие повышение мотивации также отмечади более меньшую сложность с включенностью на дистанционных лекциях (вопрос 7, где большие значения - меньшие сложности с включением).

Существенная часть студентов, отметившая снижение мотивации отмечает большие сложности ведения диалога с преподавателем и группой без возможности видеть собеседника, чем те, кто отметил прежний уровень мотивации к обучению или те, кто отметил его повышение (вопрос 8, где чем бодьше значения, тем легче вести диалог) (рис. 4). 


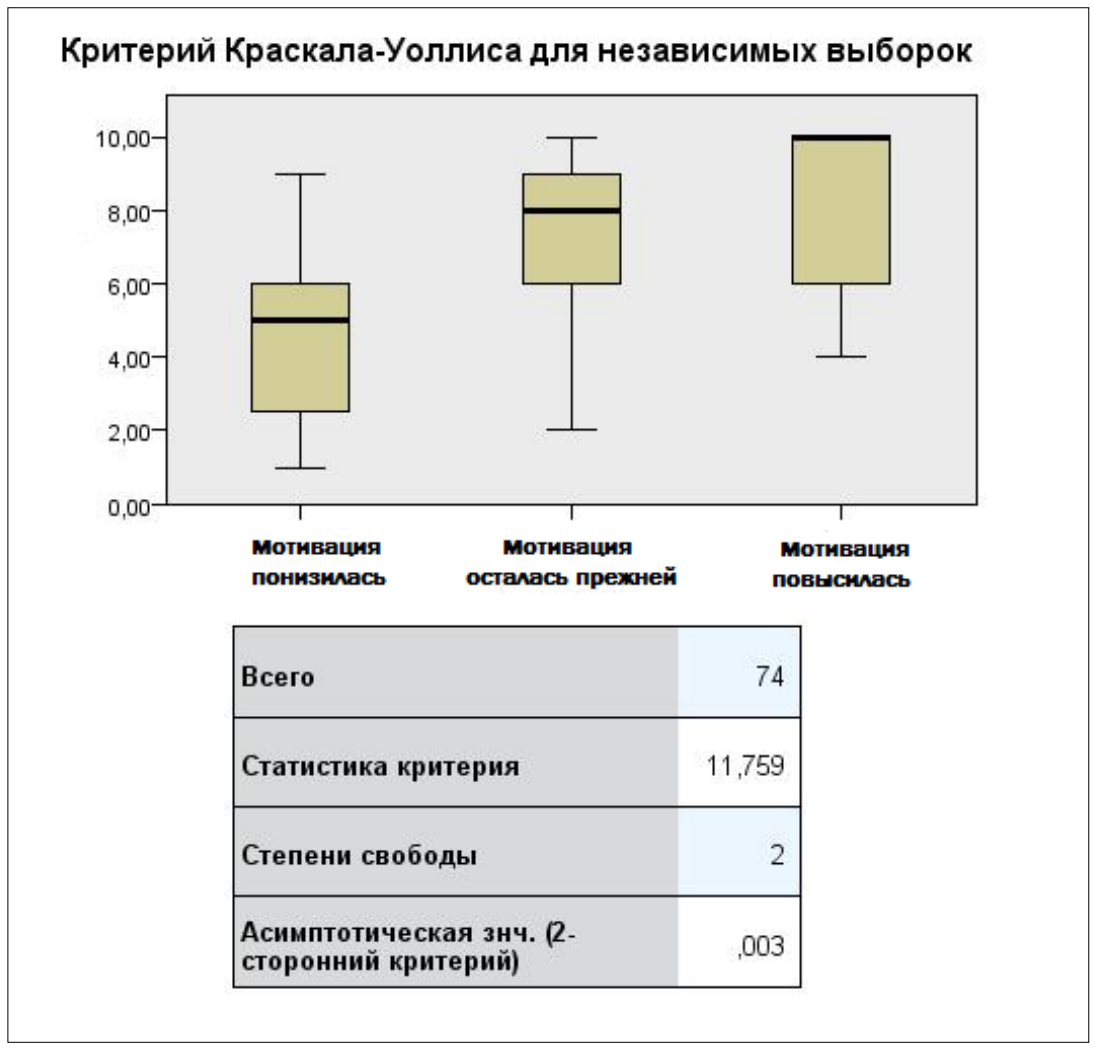

Рисунок 4. Различия по сложности ииалога без непосредственного общения

Большую удовлетворенность качеством образования после поступления в условиях карантина испытывают те, кто отметид повышение своей мотивации к обучению (вопрос 11, где чем больше значения, тем большая удовлетворенность качеством образования) по сравнению с остальными выделенными подгруппами (рис. 5). 


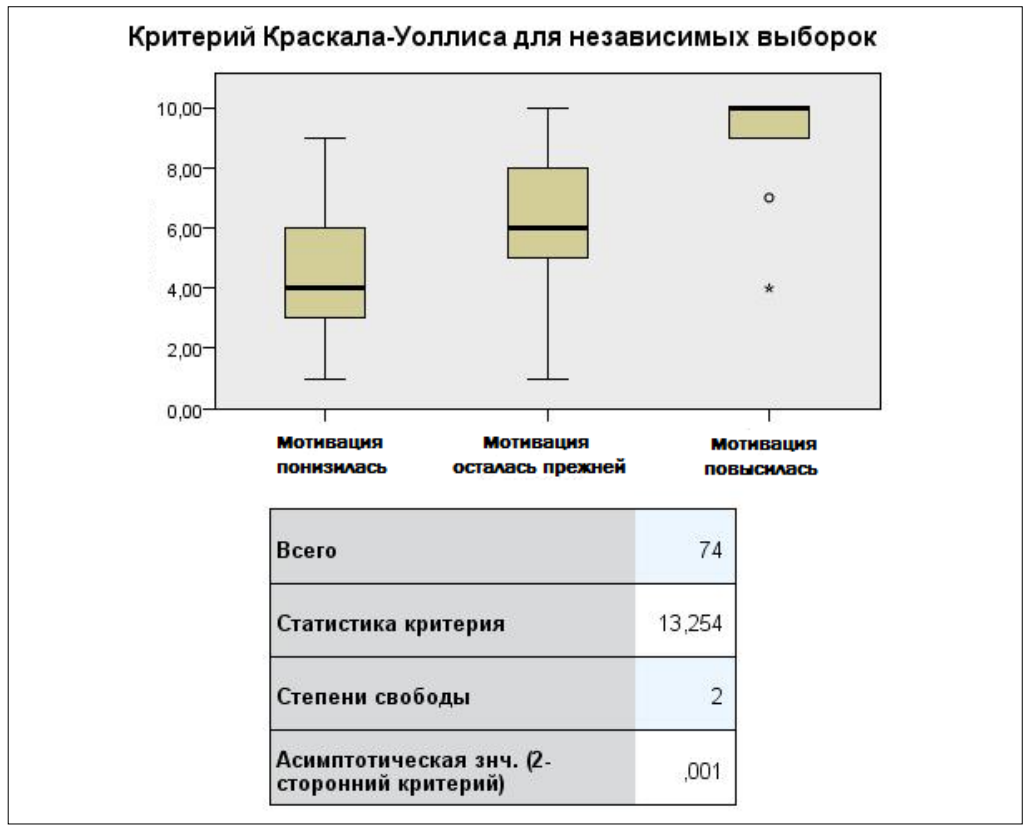

Рисунок 5. Различия удовлетворенности уровнем образования после поступления в университет

Существенных раздичий по подгруппам не было выделено для оценки значимости формата занятий при наличии собственного интереса или надичии умеющего заинтересовать преподавателя (вопросы 19 и 20 и, где большие значения - меньшая значимость формата), исходя из этого, можно сказать, что вне зависимости от изменений в уровне мотивации степень значимости формата обучения при упомянутых выше условиях существенно не раздична.

\section{Обсуждение результатов}

В результате проведенного исследования удалось рассмотреть раздичные аспекты проявления академической мотивации, а также рассмотреть ее совместно со смысложизненными ориентациями, и рассмотреть ее особенности при учете смешанного формата обучения у студентов первого курса.

Были рассмотрены получившиеся результаты, при помощи описательной статистики, по анкете-опроснику, которые показали, что большая часть студентов отмечает у себя прежний, как и до поступления, уровень академической мотивации. Большая часть, опрошенных нами студентов, испытывает удовольствие 
от обучения (часть в очном формате, часть в дистанционном, и большинство вне зависимости от формата), и лишь малой части обучение не приносит удовольствие, похожий результат обнаруживается в исследовании проводимом у студентов 4 курса медицинского вуза, которые в большинстве своем получают удовольствие от обучения (Голубкова, Смирнова, Платонова, 2018).

Также было выяснено, что при смешанном формате обучения респонденты в большинстве не ощущают отчужденности от образовательного процесса, и не испытывают сильного дискомфорта при проведении дистанционных занятий, без возможности видеть собеседника. Похожие результаты быди получены в ходе исследования Н. В. Иванушкиной, где значительная часть студентов испытывают комфорт на дистанционных занятиях. Также бодьшая часть респондентов, как и в нашем исследовании, где большинство предпочло бы продолжить обучаться в смешанном формате, относится положительно к данному формату (Иванушкина, 2021). Однако в исследовании Д. В. Бочарникова с соавторами большая часть опрошенных студентов педагогического университета предпочитает традиционную (очную) форму обучения (Бочарников, Щербакова, Щербакова, 2021). Вопрос закдючается в том, может ли предпочитаемая форма обучения зависеть от специализации обучения или же от других факторов нуждается в дополнительном исследовании.

Было выявлено, в большинстве своем респонденты не считают, что формат обучения является важным при наличии у них собственного интереса или вовлеченного в предмет преподавателя. В исследовании студентов-агрономов первого курса, обучающихся изначально в смешанной форме также был выявлен вклад роли преподавателя в качестве мотиватора (Жученко, Малахова, 2020). В другом исследовании в качестве наиболее сильных мотиваторов выявлены внутренние причины, связанные с личностным смыслом к предмету, и, один из пересекающихся с нашим исследованием результатов,-с ролью преподавателя (Китова, Трошкин, 2020).

При применении коэффициента корреляции r-Пирсона были установлены значимые корреляции, которые позволили выяснить, что более высокий уровень осмысленности жизни наблюдается у тех студентов, кто имеет более высокую мотивацию познания. Так же была обнаружена тенденция к тому, что чем более осмыслена учебная деятельность и чем больший к ней возникает интерес у студента, тем менее будет значим формат проведения занятий.

Благодаря применению критерия Н Краскала - Уоллеса было установлено, что студенты, отметившие повышение мотивации к обучению, более удовлетворены качеством образования, испытывают большее желания делать задания для дистанционных занятий, и имеют меньшие сложности с опосредованным технологиями сообщением, в большой степени ощущают себя в едином образовательном пространстве. Те же, кто отметил прежний уровень мотивации, 
ПЕДАГОГИЧЕСКАЯ ПСИХОЯОГИЯ

имеют меньшие показатели, и самые низкие имеют те, кто отметил снижение мотивации к обучению в смешанном формате. Также было выявлено, что вне зависимости от изменений в мотивации, исследуемые студенты не считают значимым формат обучения, при наличии заинтересованного в предмете преподавателя или личностного смысла у студента.

\section{Закдючение}

Проведенное исследование позводило ряд аспектов восприятия смешанного формата обучения студентами 1 курса, которые поступиди в университет в условиях ограничений, связанных с пандемией COVID-19. Результаты показывают, что у большинства студентов желание получить высшее образование и мотивация к обучению не снизились, у подавляющего большинства не возникает чувства отчужденности от процесса обучения, две трети студентов получают удоводьствие от обучения вне зависимости от формат обучения. Дистанционные занятия в рамках смешанного обучения не приводят у бодьшинства студентов к снижению ощущения единства с группой, подавляющее большинство ощущают себя пребывающими в едином образовательном пространстве с другими студентами и преподавателями, большинству легко вести диалог в дистанционном формате проведения занятий. При этом большинство студентов $(71,6 \%)$ хотели бы продолжать обучение именно в смешанном формате, с надичием в расписании аудиторных занятий. Таким образом, студенты 1 курса набора 2020 года, не имеющие опыта полноценного посещения занятий в аудиториях, положительно относятся к смешанному формат, воспринимая его как должное, и при этом не готовы обучаться полностью дистанционного, как и подностью очно.

Данное исследование носит пилотный характер и имеет ограничения, связанные с небольшой выборкой, наличием в выборке только студентов гуманитарного направления из одного университета.

Перспективы исследования связаны с дальнейшими изменениями форматов обучения - возвращения полного очного обучения в связи с ослаблениями антивирусных ограничений и изучением возникающих в связи с этим у обучающихся психологических эффектов.

\section{Автор заявдяет об отсутствии конфдикта интересов.}

\section{Дитература}

Балашова, И. В. (2021). Использование принципов смешанного обучения в организации образовательного процесса в неязыковом вузе. Заметки ученого, 2, 127-131.

Баранов, Г. А. (2020). Обучение в новой нормальности: вызовы и ответы. М.: АНО ДПО «Корпоративный университет Сбербанка». 
Бочарников, Д. В., Щербакова, Е. В., и Щербакова, Т. Н. (2014). Организация смешанной формы обучения студентов педагогического вуза. Современное педагогическое образование, 4, 173-176.

Гордеева, Т. О., Сычев, О. А., Осин, Е. Н. (2014). Опросник “Шкалы академической мотивации". Психологический журнал, 35(4), 96-107.

Жученко, О. А., Малахова, О.Н.(2020). Повышение уровня познавательной мотивации будущих профессионалов аграрного вуза в смешанном обучении. Пензенский психологический вестник, 14, 3-16. doi: 10.17689/psy-2020.1.1

Иванушкина, Н. В. (2021). Исследование специфики организации онлайнобучения в вузе. Известия Самарского научного изентра Российской академии наук. Социильные, гуманитарные, медико-биологические науки, 76, 18-22.

Кречетников, К. Г. (2019). Особенности организации смешанного обучения. Современные проблемы науки и образования, 4.

Деонтьев, Д. А. (2000). Тест смысложизненных ориентациий (СЖО). М.: Смысл.

Носкова, М. В., Бескова, А. С., и Булыгина, А. В. (2016). От академической мотивации обучающихся к качеству образования. Вестник Уральского государственного медицинского университета, 4, 80-83.

Цибульникова, В. Ю. (2021). Архитектура обучающей среды как основа мотивации студентов к активному обучению. В Современное образование: повышение конкурентоспособности университетов. Материалы международной научно-методической конференции в 2 частях (С. 202-206). Томск: ТГУСиР.

Швецова, Т. Н. (2020). К вопросу мотивации студентов в условиях реализации образовательного процесса в дистанционном формате. В Социально-экономическое развитие России: проблемы, тенденциии, перспективы. Сборник научных статей 19-й Международной научно-практической конференции (С. 279-281). Курск: ФУ при Правительстве РФ, Курский филиал.

Deci, E., Ryan, R. (2008). Facilitating Optimal Motivation and Psychological WellBeing Across Life's Domains. Canadian Psychology, 1, 14-23.

Long, N. T., Van Hanh, N. (2020). structural equation model of blended learning culture in the classroom. International Journal of Higher Education, 9(4), 99-115. https:// doi.org/10.5430/ijhe.v9n4p99

Pannan, L. J., Legge, K. A. (2016). A blended learning model and a design model combine to support academics in pedagogical redesign of the curriculum. In ASCILITE 2016. Conference Proceedings of the 33rd International Conference of Innovation, Practice and Research in the Use of Educational Technologies in Tertiary Education: Show Me the Learning (pp. 487-497). Adelaide.

Staker, H., Horn, M. (2012). Classifying K-12 Blended Learning. Innosight Institute.

\section{References}

Balashova, I. V. (2021). Using the principles of blended learning in the organization 
ПЕДАГОГИЧЕСКАЯ ПСИХОЯОГИЯ

of the educational process in a non-linguistic university. Scientist's Notes, 2, 127-131.

Baranov, G. A. (2020). Learning in the New Normal: Challenges and Responses. Moscow: ANO DPO "Corporate University of Sberbank".

Bocharnikov, D. V., Shcherbakova, E. V., \& Shcherbakova, T. N. (2014). Organization of a mixed form of education for students of a pedagogical university. Modern teacher education, 4, 173-176.

Deci, E., Ryan, R. (2008). Facilitating Optimal Motivation and Psychological WellBeing Across Life's Domains. Canadian Psychology, 1, 14-23.

Gordeeva, T. O., Sychev, O. A. \& Osin, E. N. (2014). Questionnaire "Scales of academic motivation". Psychological Journal, 35 (4), 96-107.

Ivanushkina, N. V. (2021). Research of the specifics of the organization of online education at the university. Bulletin of the Samara Scientific Center of the Russian Academy of Sciences. Social, humanities, biomedical sciences, 76, 18-22.

Krechetnikov, K. G. (2019). Features of the organization of blended learning. Modern problems of science and education, 4.

Leontiev, D. A. (2000). Life-Meaning Orientation Test (LSS). Moscow: Meaning.

Long, N. T., Van Hanh, N. (2020). structural equation model of blended learning culture in the classroom. International Journal of Higher Education, 9(4), 99-115. https:// doi.org/10.5430/ijhe.v9n4p99

Noskova, M. V., Beskova, A. S., and Bulygina, D. V. (2016). From academic motivation of students to the quality of education. Bulletin of the Ural State Medical University, 4, 80-83.

Pannan, L. J., Legge, K. A. (2016). A blended learning model and a design model combine to support academics in pedagogical redesign of the curriculum. In ASCILITE 2016. Conference Proceedings of the 33rd International Conference of Innovation, Practice and Research in the Use of Educational Technologies in Tertiary Education: Show Me the Learning (pp. 487-497). Adelaide.

Shvetsova, T. N. (2020). On the issue of motivating students in the context of the implementation of the educational process in a distance format. In Socio-economic development of Russia: problems, trends, prospects. Collection of scientific articles of the 19th International Scientific and Practical Conference (pp. 279-281). Kursk: Federal University under the Government of the Russian Federation, Kursk branch.

Staker, H., Horn, M. (2012). Classifying K-12 Blended Learning. Innosight Institute.

Tsibulnikova, V. Yu. (2021). The architecture of the learning environment as the basis for motivating students to active learning. In Modern education: increasing the competitiveness of universities. Conference Proceedings of the international scientific and methodological conference in 2 parts (pp. 202-206). Tomsk: TSUSiR.

Zhuchenko, O. A. \& Malakhova, O. N. (2020). Increasing the level of cognitive motivation of future professionals of an agricultural university in blended learning. Penza psychological bulletin, 14, 3-16. doi: 10.17689/psy-2020.1.1 